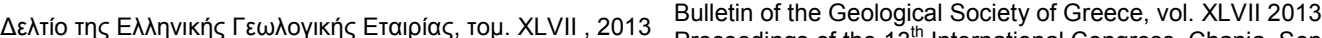
Proceedings of the $13^{\text {th }}$ International Congress, Chania, Sept.

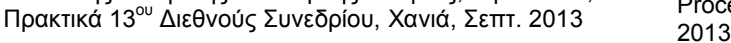

\title{
GROUND PENETRATING RADAR AND ELECTRICAL RESISTIVITY TOMOGRAPHY FOR LOCATING BURIED BUILDING FOUNDATIONS: A CASE STUDY IN THE CITY CENTRE OF THESSALONIKI, GREECE
}

\author{
Vargemezis G. ${ }^{1}$, Diamanti N. ${ }^{1}$, Fikos I. ${ }^{1}$, Stampolidis A. ${ }^{1}$, Makedon Th. ${ }^{2}$ and \\ Chatzigogos $\mathbf{N}$. \\ ${ }^{I}$ Aristotle University of Thessaloniki, School of Geology, Department of Geophysics, GR-54124, \\ POBox352-1, Thessaloniki, Greece,ndiamant@geo.auth.gr,varge@geo.auth.gr, \\ ifikos@geo.auth.gr,astamp@geo.auth.gr \\ ${ }^{2}$ Aristotle University of Thessaloniki, School of Geology, Department of Geology, GR-54124, \\ Thessaloniki,Greece,thomas@geo.auth.gr; chatzi12@gmail.com
}

\begin{abstract}
Ground penetrating radar (GPR) and electrical resistivity tomography (ERT) surveys have been carried out in the city centre of Thessaloniki (N. Greece), for investigating possible locations of buried building foundations. Geophysical survey has been chosen as a non-destructive investigation method since the area is currently used as a car parking and it is covered by asphalt. The geoelectrical sections derived from ERT data in combination with the GPR profiles provided a broad view of the subsurface. Regarding ERT, high resistivity values can be related to buried building remains, while lower resistivity values are more related to the surrounding geological materials. GPR surveying can also indicate man-made structures buried in the ground. Even though the two geophysical methods are affected in different ways by the subsurface conditions, the processed underground images from both techniques revealed great similarity. High resistivity anomalies and distinct GPR signals were observed in certain locations of the area under investigation, which are attributed to buried building foundations as well as the geological structure of the area.
\end{abstract}

Key words: Archaeological prospection, geophysical survey, non-destructive testing, GPR, ERT.

\section{Пєрí $\eta \psi \eta$}

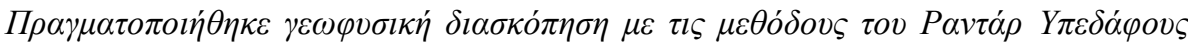

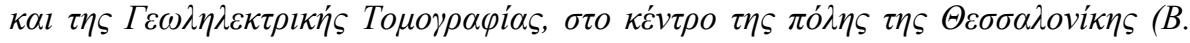

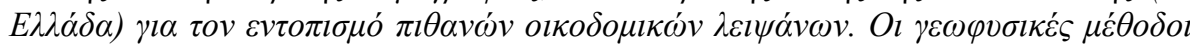

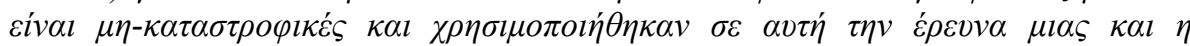

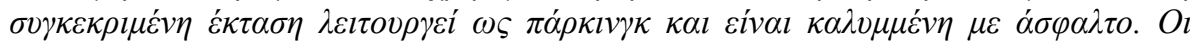

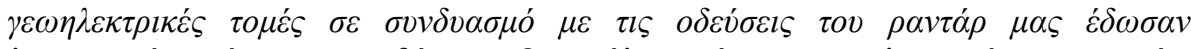

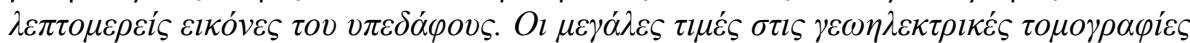

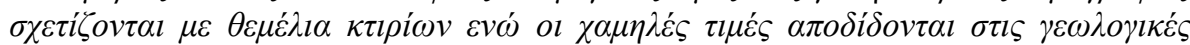

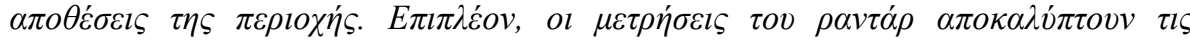

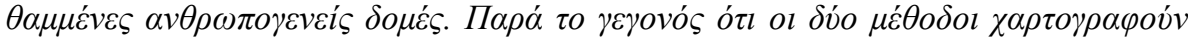

XLVII, No $3-1355$ 


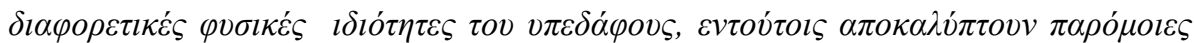

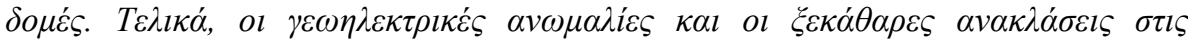

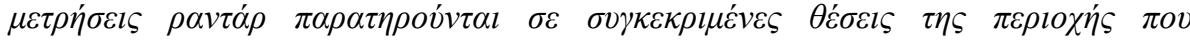

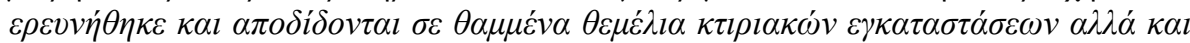
v

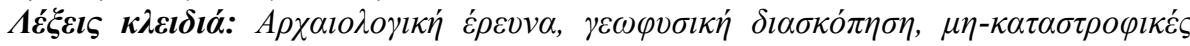

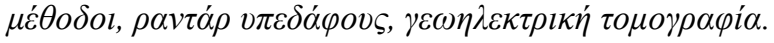

\section{Introduction}

It is well documented during the last decades that geophysical prospecting is increasingly used for detecting and mapping buried archaeological remains and standing monuments. Further, the combination of geophysical methods offers high resolution, detecting features in the order of a few tens of centimetres depth and/or thickness to several metres. Resistivity methods, and more specifically electrical resistivity tomography (ERT), (Tsokas et al., 1994; Diamanti et al., 2005, Papadopoulos et al., 2007, Tsokas et al., 2008a, Tsourlos and Tsokas, 2011) and ground penetrating radar (GPR) (Savvaidis et al., 1999; Leucci, 2002; Piro et al., 2003; Linford, 2004; Tsokas et al., 2007) are two of the most popular methods for doing so.

In this study we present the geophysical survey which was carried out at the parking area situated at the junction of Tsimiski St. and Ethnikis Aminis St., in the city centre of Thessaloniki (N. Greece). This survey was conducted in the framework for the construction of a new, underground parking area below the current one. There are records regarding modern building foundations in the area. The aim of the presented geophysical survey was (a) to study the subsurface geological structures at the location of the parking area and (b) to detect and possibly map buried antiquities under the ground surface. The case presented here comprises an example of a combined geophysical survey for investigating the area of interest. The geophysical methods employed were: ERT and GPR.

\section{Geophysical Methods}

\subsection{Electrical Resistivity Tomography (ERT)}

Resistivity techniques are established and widely used to solve a variety of geotechnical, geological and environmental subsurface detection problems. The goal of resistivity methods is to measure the potential differences on the ground surface due to the current flow within the ground. This measured potential drop reflects the difficulty with which the electrical current flows within the subsurface and hence, it gives an indication of the earth's electrical resistivity. Knowledge of the subsurface material resistivity is used for distinguishing existing underground features, such as layering, voids, man-made structures etc.

ERT can be considered as the development of the standard geoelectrical method. The advent of fully automated measuring instruments with electrode multiplexing ability in combination with the development of advanced interpretation algorithms, allows the collection of a large amount of data and the production of electrical resistivity images of the subsurface. The rapid advanced in computer technology during the last decades, allowed the development of automated algorithms, known as inversion algorithms, which are able to create precise images of subsurface resistivity distribution (Tripp et al., 1984; Li and Oldenburgh, 1992; Tsourlos, 1995).

ERT has proved to be a successful method in providing fast and reliable shallow subsurface geoelectrical property images under various field conditions, even in complex geological environments. ERT has been extensively employed in various cases such as in archaeological, geological and hydrogeological studies (Tsourlos et al., 2003; Tsokas et al., 2008b; Vargemezis et al., 2007, Ogilvy et al., 2009; Vargemezis et al., 2009).

$\underline{\text { XLVII. No } 3-1356}$ 


\subsection{Ground Penetrating Radar (GPR)}

GPR is the general term applied to techniques which employ radio waves, typically in the 1 to $1000 \mathrm{MHz}$ frequency range, to map structures and features buried in the ground (or in man-made structures). A GPR unit sends out radio waves that partially reflect back when they meet objects

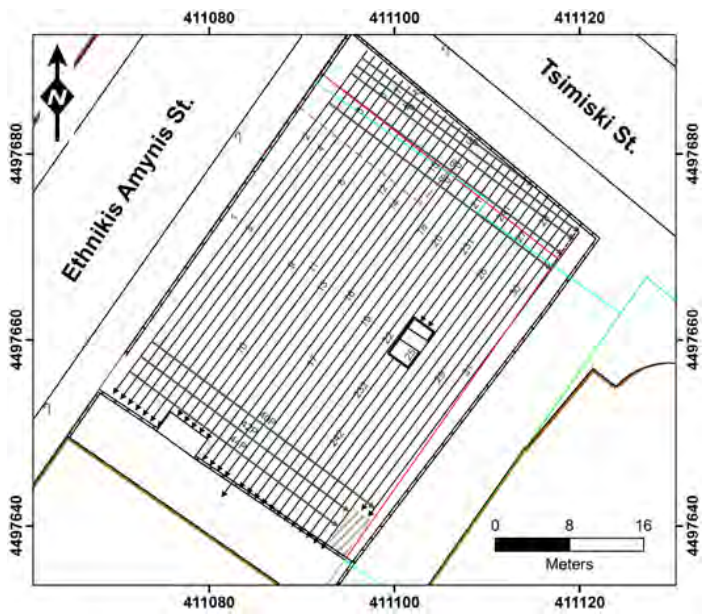

Figure 1 - (a) Plan view of the studied area (arbitrary coordinate system-coordinates in meters). Solid black lines denote the location $\&$ arrows the direction of ERT sections.

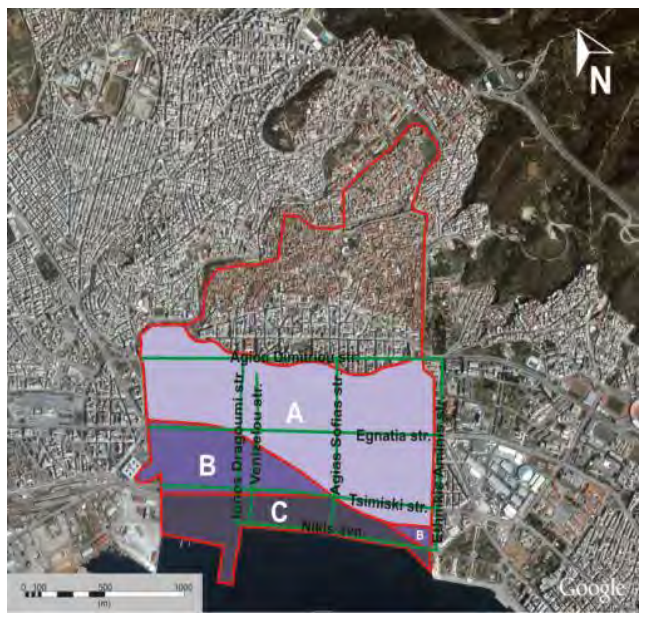

(b) Subdivisions of Thessaloniki's urban fil (implemented classification scheme proposed by Chatzigogos et al., 2006). Class $A$ : Historical fill, Class B: Modern fill (1 coastal expansion), Class $C$ : Modern fill $\left(2^{\text {nd }}\right.$ coastal expansion).

electrically different than their surroundings, and partially propagate in deeper layers. By recording the time interval between the instant at which the pulse is emitted by the transmitter and is recorded by the receiver, and by knowing its propagation velocity in the subsurface, it is possible to map underground reflectors.

GPR data is typically displayed in a cross-sectional format. We can also create three-dimensional (3D) views of data and also two-dimensional (2D) depth slices using appropriate software. These subsurface slices show how GPR signals vary over a grid area at a certain depth and they are very useful for data interpretation because they can reveal patterns that were not easily recognized while analyzing the cross-sections.

Today GPR is being used in many different areas including locating buried utilities, mine site evaluation, road / bridge / tunnel inspection, forensic investigations, archaeological digs, searching for buried landmines and unexploded ordinances, measuring snow, ice thickness, quality for ski slope management and avalanche prediction (Davis and Annan, 1989; Colla et al., 1997; Guy et al., 2000; Spikes et al., 2004; Diamanti et al., 2008; Solla et al., 2010; Diamanti and Redman, 2012).

\section{Geophysical Survey}

The geophysical prospecting using ERT and GPR was carried out simultaneously for both methods. One of our goals was to obtain indirect information regarding the near surface and deeper geometry and lithology of the subsurface at the area under study. The site is located just outside the SE part of the ancient city walls. According to geological information, the anticipated stratigraphy comprises of a superficial urban-historical fill of 2-4m thickness, overlying a 4-6m thick soil formation consisting of coastal river deposits (mostly sandy clays to clayey sands with calcareous bodies and rubble). The characteristic red-clay formation of Thessaloniki is expected to 
be found $5-7 \mathrm{~m}$ deep (Anastasiadis et al., 2001). In addition, the site is located very close to the natural coastline of the city, as illustrated in Figure 1b (Chatzigogos et al., 2006). This geophysical survey was part of a more extensive campaign of geological / geotechnical investigations at the area of interest.

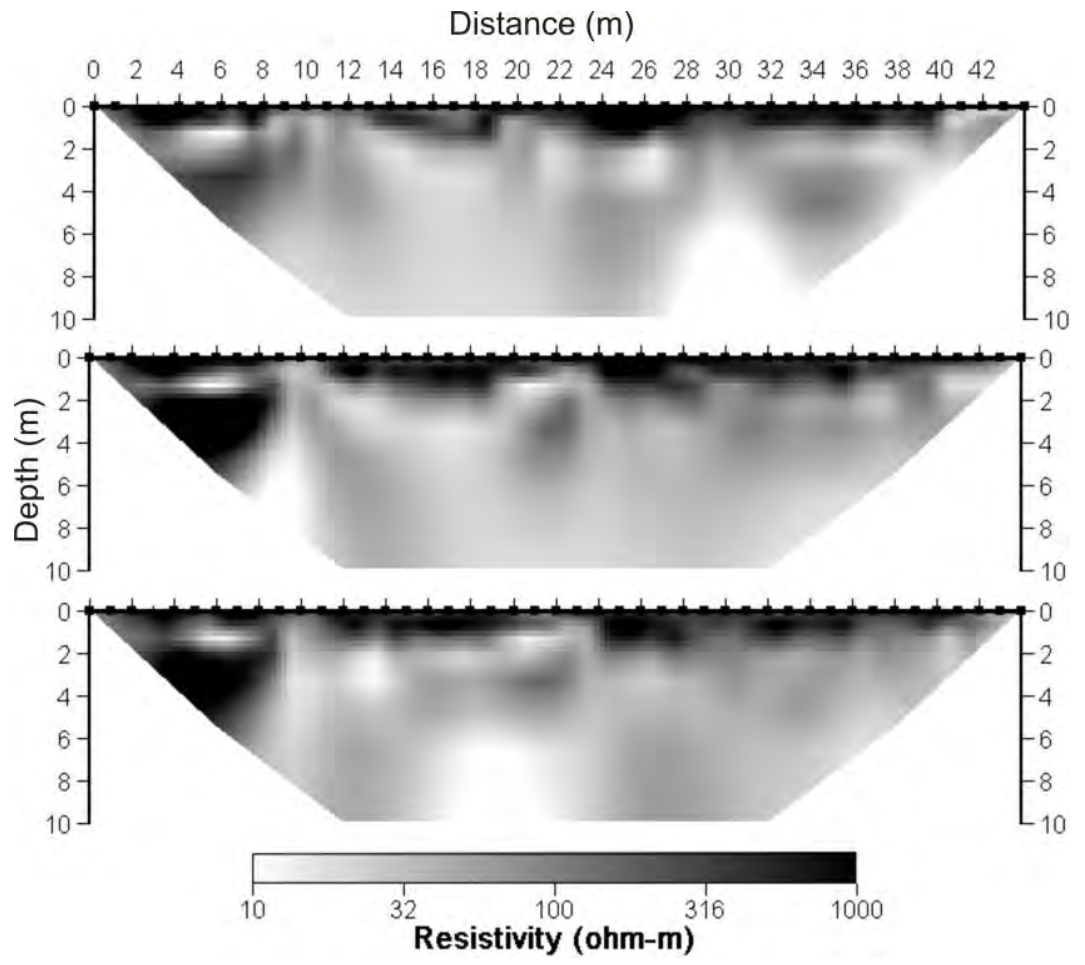

Figure 2 - Examples of the inverted ERT sections 1 to 3 (top to bottom). Depth (left vertical axis) and distance (horizontal axis) are in metres.

\subsection{ERT: Data Acquisition, Processing and Results}

The surface geological formations at the area of interest allowed for an effective ERT survey since the subsurface resistivity is expected to be small compared to the resistivity of the buried building foundations and antiquities.

We decided on the acquisition parameters of all geoelectrical tomographies so as to achieve $\sim 10$ meters depth of investigation. For the measurements we used the Iris Syscal-Pro resistivity meter. It has to be noted that a very important factor for the good quality of ERT measurements is the contact resistance between electrodes inserted into the ground and soil material. This quantity needs to be small so as electrical currents are easier injected into the subsurface. In our case, the ground is covered with asphalt which is a material completely unsuitable for current propagation. In order to restore direct coupling between the electrodes and the subsoil, we decided to drill the asphalt at the locations where the electrodes would be mounted to the ground.

Given the three-dimensional nature of the problem studied, we decided to acquire dense survey lines, to allow full 3D processing of the data (Papadopoulos et al., 2006). We measured a dense grid of parallel - and a few perpendicular - 2D ERT lines. We collected thirty-one linear ERTs in one direction (Figure 1a - NE-SW lines) and eight tomographies perpendicular to the first ones (Figure 1a - lines located almost parallel to Tsimiski St.), all being $1 \mathrm{~m}$ away from the other. We chose the dipole-dipole array to perform the survey as it has a good signal to noise ratio, provides the highest resolution and is most sensitive to vertical resistivity boundaries (Griffiths and Barker, 1993). The maximum potential to current electrode separation was $n=8$ (i.e., eight times the length 
of the potential measuring dipole). The inter-electrode spacing was set to a=1.0 $\mathrm{m}$ for all ERT sections. In this way, we achieved a maximum penetration depth without sacrificing the resolution.

All measured ERT sections were inverted using DC2dPro (Kim, 2009), while a 3D resistivity model was constructed with DC3dPro (Yi et al., 2001). ERT data were collected on a grid and

(a)

Distance $(m)$

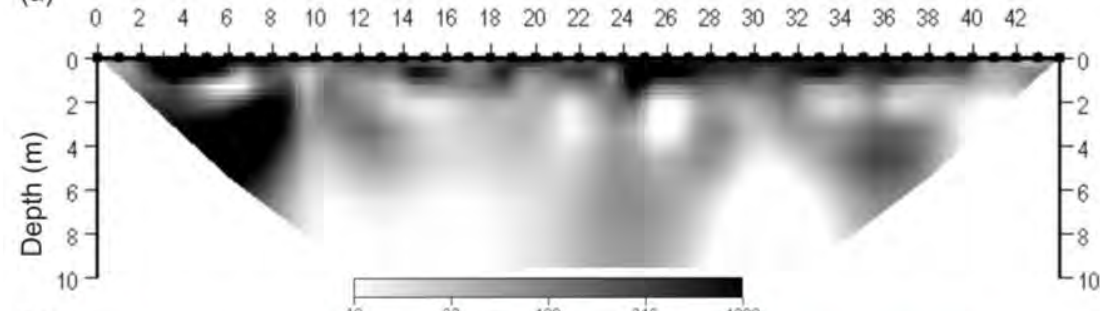

(b)
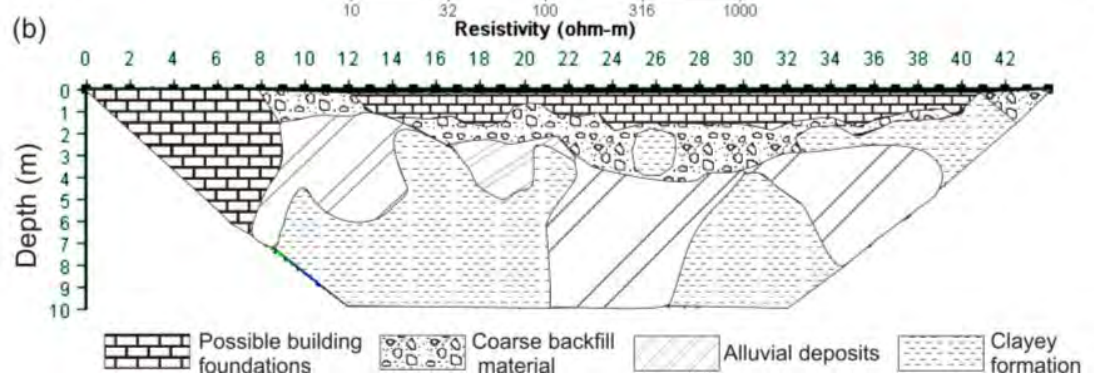

Figure 3 - (a) An inverted ERT section and (b) its possible interpretation.

therefore, apart from the traditional 2D inversion, it was possible to perform 3D processing and presentation of results, which is closer to reality. The 2D and 3D inversion schemes perform an iterative optimization based on a finite element forward modelling scheme. All inversions produced a low misfit error between the real and the predicted data $(3 \%)$.

Figure 2 presents the inverted results of three indicative geoelectrical sections (the first three lines of Figure 1a, from NE towards SW). All ERT data are presented in either linear or logarithmic grey or rainbow scale. The x-axis of the ERT section is the horizontal distance along the survey line, while the y-axis is the depth, both in metres. All the inverted results of the $2 \mathrm{D}$ datasets obtained, depict a similar, characteristic variation in the subsurface resistivity. There seem to be horizontal layering consisting of areas of high resistivity, which is expected at the locations of building foundations. These areas differ significantly from the underlying clay layer. The corresponding layer for the backfill material has strong resistivity variations due to its heterogeneity.

An example of the inversion results with its interpretation is shown in Figure 3. As stated, the building ruins seem to cause a distinctive geoelectrical anomaly which is much different than the one caused by the surrounding formations. The thickness of the layer consisting of backfill / building foundation materials varies and its resistivity ranges from $\sim 100$ to $\sim 1000 \mathrm{Ohm}-\mathrm{m}$, since it consists of various materials (e.g., aggregates, cement blocks etc.). In most cases, the building foundations are located at a depth up to $\sim 5$ metres. Below this depth, there is a geological formation with resistivity ranging from $\sim 10 \mathrm{Ohm}-\mathrm{m}$ - which corresponds to clay materials - to $\sim 80-100$ Ohm-m - which are values mainly matching materials such as sand, gravel, boulders and in general alluvial deposits (coarser materials).

As discussed previously, resistivity variation is in reality fully $3 \mathrm{D}$. So, in the studied area, we collected parallel 2D ERT lines which were processed with a fully 3D approach, i.e. they were inverted altogether with the DC3dPro inversion software (Yi et al., 2001). The processing scheme

$\underline{\text { XLVII, No } 3-1359}$ 
is based on a 3D finite element forward modelling solver. Note that this approach is much more time-consuming compared to the $2 \mathrm{D}$ one and can be applied only in areas where several parallel ERT lines (i.e., > 4) are collected. Although the data acquisition is a set of 2D measuring sections, it has been shown that in this case fully $3 \mathrm{D}$ imaging is possible when inversion is performed by fully 3D algorithms (Papadopoulos et al., 2006; 2007). Also, the data have to be collected along dense parallel traverses, which ideally should be spaced at intervals equal to the spacing of the electrodes along the traverse. Both these constraints are fulfilled in our case.
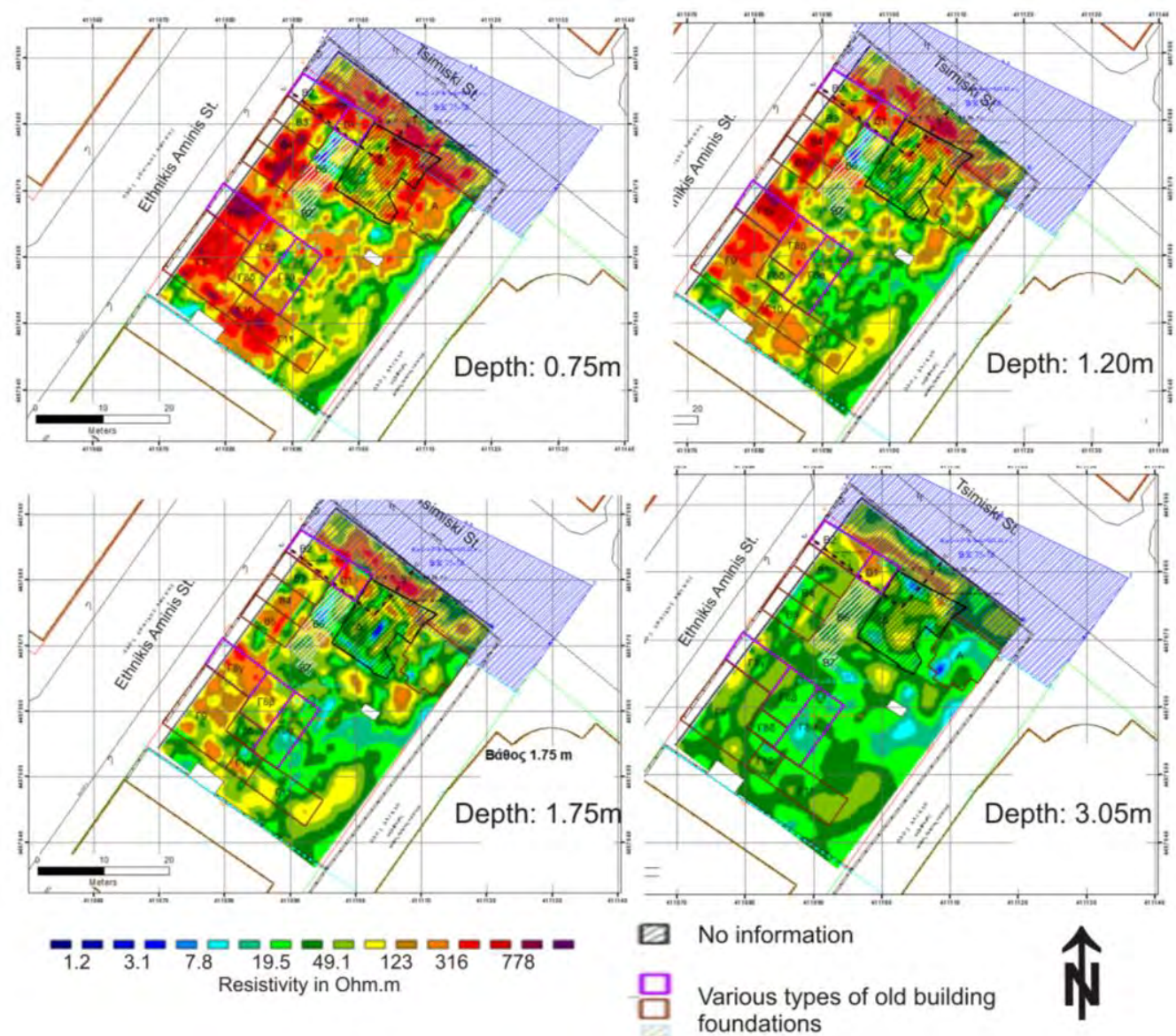

Figure 4 -Depth slices derived from the full $3 D$ inversion of the set of ERT sections.

In Figure 4, two-dimensional depth-slices derived from the full three-dimensional inversion of the set of tomographies are presented. The highly resistive outline of the building foundations is clearly distinguished from the less resistive geological materials. The building remains are mainly located up to a depth of 2.5 metres, with the exception of the northern part (parallel to Tsimiski St.) where they extend up to 4.5 metres but with significantly lower values of resistivity. In Figure 5 , the three-dimensional resistivity volume for the high and low resistivity values is presented: the high resistivity $3 \mathrm{D}$ image delineates realistically the building remains in contrast to the low resistivity image, which corresponds to the surrounding geological formations.

\subsection{GPR: Data Acquisition, Processing and Results}

We employed GPR to obtain higher resolution images of the subsurface than the ones we got using the ERT technology. We collected fifty-eight GPR profiles on the same locations and acquisition direction as the ERT sections (the sections with direction from NE to SW only-Figure 1a) and also 
between them. So, each GPR profile was $0.5 \mathrm{~m}$ apart from the other. We used a cart-based 500 $\mathrm{MHz}$ GPR system produced by Mala. The trace sampling interval was $0.05 \mathrm{~m}$. We present our GPR data in the standard cross-sectional format. Position is plotted on the horizontal axis, and depth and time on the vertical axes. To convert the time axis into depth, we assumed a constant signal velocity which. This velocity was set equal to $0.11 \mathrm{~m} / \mathrm{ns}$ and it was determined by using a GPR velocity analysis software by Sensors \& Software Inc. Moreover, we present our data as plan view maps (i.e., time/depth slices) which is one of the most widely used way of GPR data presentation, especially in archaeological prospection (Goodman et al., 1995).
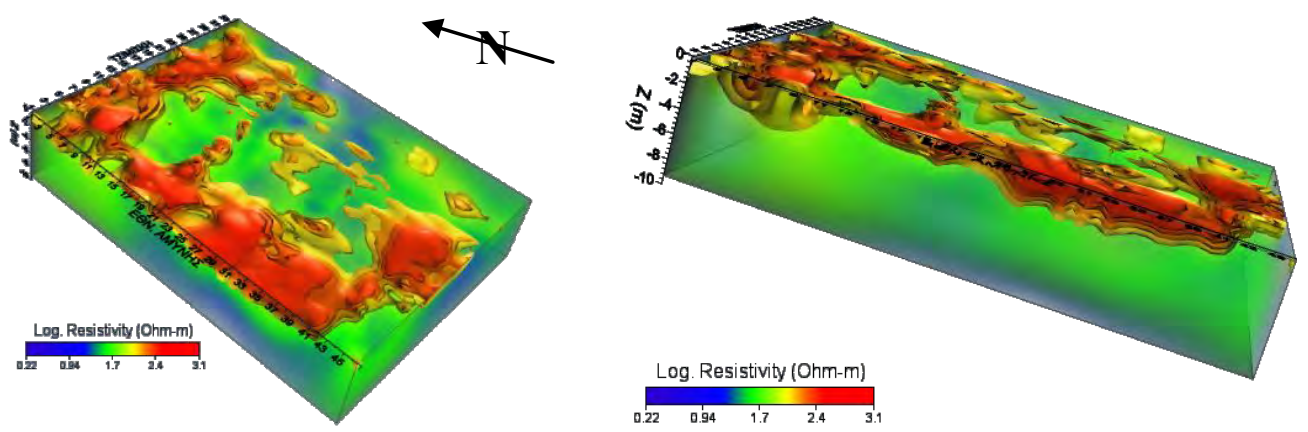

Figure 5-Three-dimensional geoelectrical views of the subsurface. The bold red colours represent old building foundations under the studied area at various depths.

All GPR profiles were processed using Sensors \& Software Inc. software, while the depth slices were produced using the software GPR-SLICE. We applied the same processing to all GPR sections and we purposely used a uniform signal velocity for comparisons between them. We applied a standard dewow filter to remove very low frequency components from the field data. Since GPR signals are very rapidly attenuated as they propagate into the ground, we applied a time dependent gain function to the data to compensate for this decrease in GPR signals from greater depths. We have applied a spherical exponential compensation (SEC) gain to enhance features in the data. We have also applied temporal filtering to the data to remove unwanted frequencies from our signals and to improve data quality and assist interpretation. It should be noted that all indications of targets presented in GPR data are true anomalies even though they may not be the desired targets. Similarly to all geophysical methods, GPR is incapable of giving a false positive reading, which is where experience in reading the records can help the investigator.

Figure 6 presents three cross-sections acquired from NE to SW at various locations of the survey area. Looking at the GPR profiles, it seems that we can obtain a reliable subsurface image up to a depth of $\sim 2.0-2.5$ metres. In all fifty-eight profiles collected in this area, we observe various reflections that could be possibly caused by old buildings foundations. Even though each GPR profile can be quite informative, one of the most useful presentations of GPR data sets collected along closely spaced parallel profiles is to display data in horizontal maps. These maps allow easy visualization of the location, depth, size and shape of GPR anomalies into the ground. Figure 7 presents selected depth slices developed from all GPR profiles. These slices are placed on a topographic map indicating locations of old buildings, information which was retrieved from historic records. The plan view maps show several features (orange/red colour) which are believed to be collapsed buildings/foundations.

\subsection{Combined ERT and GPR}

Even though ERT and GPR are two geophysical methods that are affected in different ways by the subsurface conditions, the processed underground images from both techniques revealed great similarity. An example is shown in Figure 8, which presents an ERT section and a GPR profile that were both acquired along the same line. Both interpreted ERT and GPR reveal similar lateral characterization (Figure 8 - white dashed line) of the near surface features. Moreover, there is a 
good agreement on the interpreted thickness / depth of the underlying building foundations between the two methods.

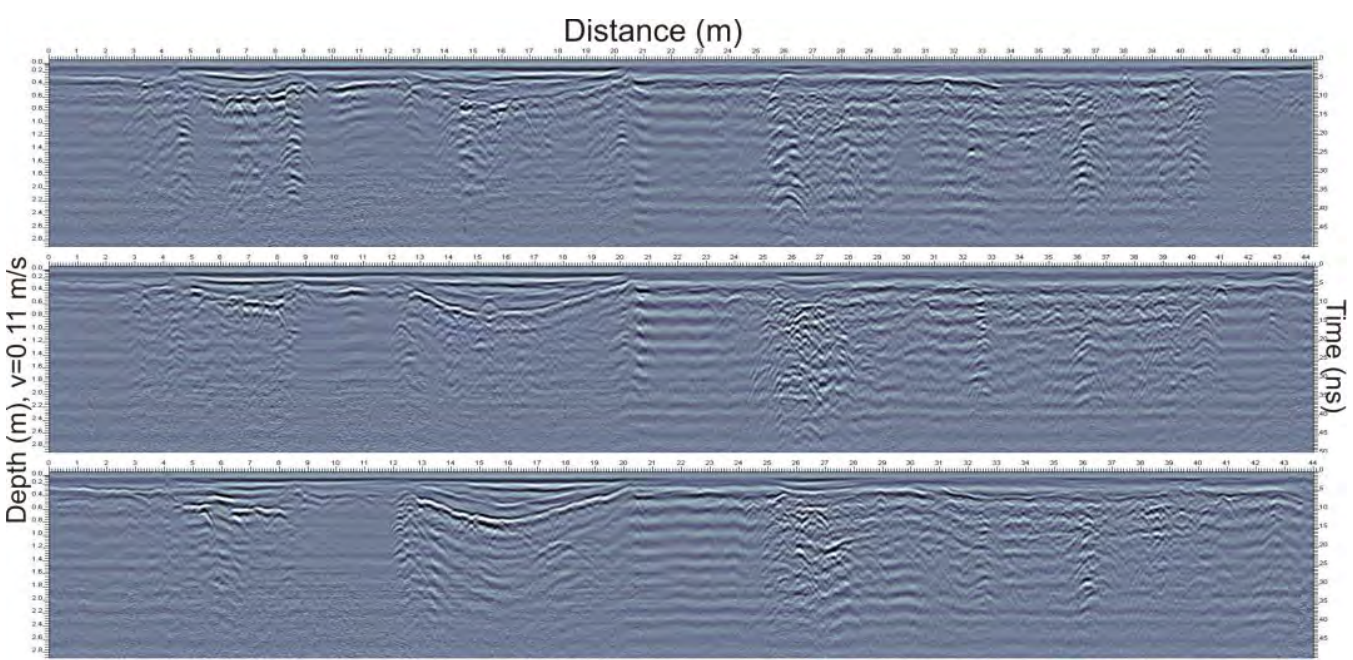

Figure 6 - GPR cross-sections acquired from NE to SW at various locations of the area.

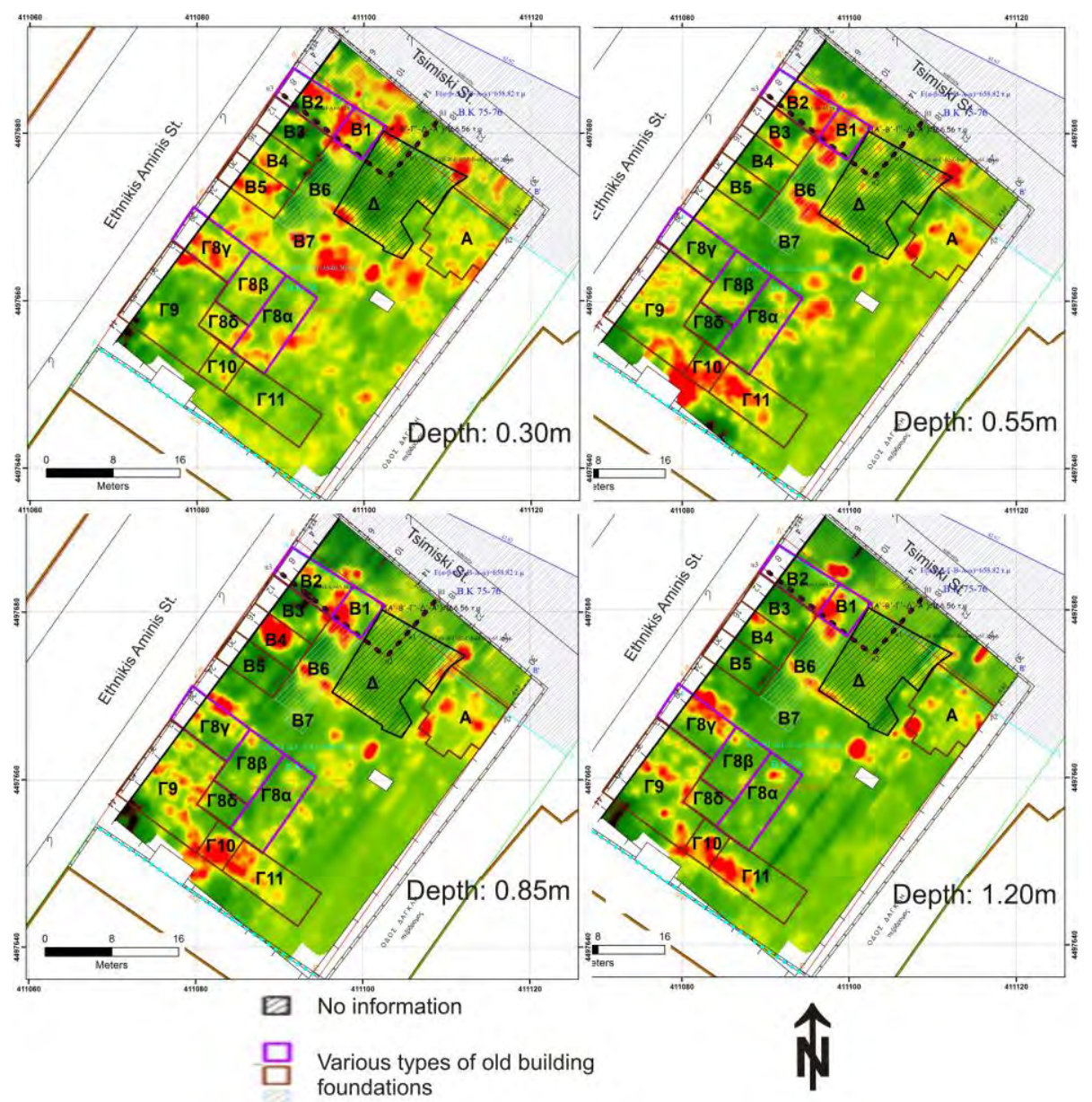

Figure 7 -GPR depth slices. Locations of old buildings are annotated on the map.

XLVII, No 3 - 1362 

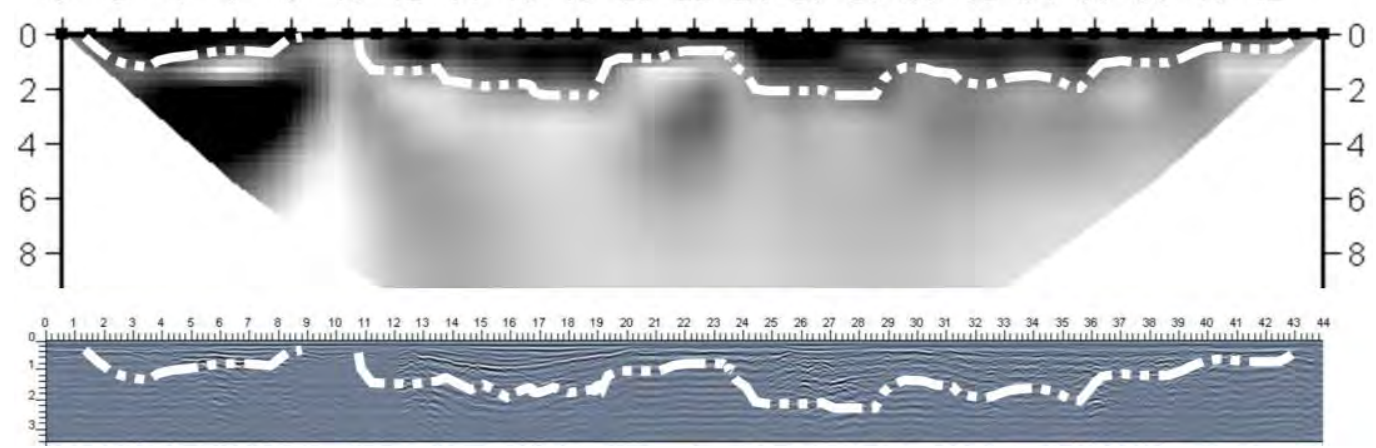

Figure 8 - An ERT section and a GPR profile acquired along the same line. The white dashed line indicates the area of similarity between the two sections.

It has to be noted that in many cases there are a few discrepancies between the depth positions of features deduced from GPR and ERT. This is due to the velocity variation of radar waves in the subsurface. GPR velocity is an average and does not remain constant while GPR waves travel in various soil conditions in the subsurface. For GPR profiles, to convert time-axis into depth-axis, we assume a constant GPR velocity and therefore, the actual depth of subsurface features is possible to slightly change from the one appearing on the vertical axis of GPR profiles and on depth slices. Though, the lateral positions of underground targets can be mapped in great detail using GPR.

Comparing both the cross-sections and depth slices of the two methods, it is obvious that ERT provides subsurface information for a greater depth than GPR, and maps quite satisfactorily the deeper subsurface geology. GPR, however, provides a more detailed image of the studied area. Both GPR profiles and depth slices image the near surface features with great resolution and detail regarding their lateral and vertical position.

\section{Summary and Conclusions}

A geophysical survey was performed in the city centre of Thessaloniki, Greece. This survey was part of a more extensive campaign of geophysical / geotechnical investigations which were carried out in the framework of the construction of new, underground parking area below the current one. We used both the ERT technique and the GPR method.

Both ERT and GPR were able to map and indicate locations of old building foundations, mainly buried near the surface. Depth slices seem to be very helpful in revealing subsurface patterns that cannot be easily seen while looking at the cross-sections of both methods. ERT cross- sections and depth slices provide a geoelectrical image of the subsurface for a greater depth than GPR. Apart from the anthropogenic structures, the ERT method also provides deeper geological subsurface information. On the other hand, GPR maps effectively features located in a smaller depth. Radar imaging provides great resolution in both lateral and vertical location of underground targets.

Based on the geological setting and the results of the geophysical investigation, the site seems to be located adjacent to a former stream-river bed running along Ethnikis Aminis St., very close to its coastal outflow. The geological model of the current survey also indicates stream cuts inside the red-clay formation (low resistivity areas) which may be branches of the outflow or estuary of the well-known Evangelistria stream. The interpretation and correlation of the geophysical results to the geological setting of the area, explains adequately the lack of archaeological ruins or findings in the specific area (despite the fact that such remains were found during the excavation of the neighbouring YMCA square to the east of the investigated site). This can be attributed to the 
presence of an ancient stream-river bed with significant flow, bordering the ancient city walls, adjacent to the investigated site which possibly prohibited ancient urban constructions.

Our results show that combined ERT and GPR investigations are useful for providing an informative geophysical image of the subsurface. ERT imaging documents geoelectrical heterogeneities and GPR signatures depend on the dielectric/electromagnetic properties of subsurface materials. In some cases, there are a few discrepancies between the depth position of features obtained from GPR data and ERT interpretations. This depth variability is possibly caused by the radar wave velocity variation in the subsurface. Nevertheless, the combined use of ERT and GPR in conjunction with any other possible information (e.g., historic records) strengthens the geophysical/geological interpretations by reducing the ambiguous results. This effectively improves the accuracy of the lateral and vertical information about the investigated terrains.

\section{References}

Anastasiadis A., Raptakis D. and Pitilakis K. 2001. Thessaloniki's Detailed Micro zoning: Subsurface Structure as Basis for Site Response Analysis, Pure and Applied Geophysics, 158, $2597-2633$.

Chatzigogos N., Makedon T., Tsotsos S. and Christaras B. 2006. Implementation of a ground investigation strategy on urban fills, Proc. of the $10^{\text {th }}$ IAEG Congress, Nottingham, U.K., 610 September.

Colla C., Dast P.C., McCann D. and Forde M.C. 1997. Sonic, electromagnetic and impulse radar investigation of stone masonry bridges, NDT\&E International, 30(4), 249-54.

Davis J.L. and Annan A.P. 1989. Ground-penetrating radar for high-resolution mapping of soil and rock stratigraphy, Geophysical Prospecting, 37, 531-551.

Diamanti N.G., Tsokas G.N., Tsourlos P.I., and Vafidis A. 2005. Integrated interpretation of geophysical data in the archaeological site of Europos (Northern Greece), Archaeological Prospection, 12, 79-91.

Diamanti N., Giannopoulos A. and Forde M.C. 2008. Numerical modelling and experimental verification of GPR to investigate ring separation in brick masonry arch bridges, NDT\&E International, 41(5), 354-363

Diamanti N. and Redman J.D. 2012. Field observations and numerical models of GPR response from vertical pavement cracks, Journal of Applied Geophysics, 81, 106-116.

Goodman D., Nishimura Y. and Rogers J.D. 1995. GPR Time Slices in Archaeological Prospection. Archaeological Prospection, 2, 85-89.

Griffiths D.H. and Barker R.D. 1993. Two-dimensional resistivity imaging and modelling in areas of complex geology, Journal of Applied Geophysics, 29, 211-226.

Guy E., Daniels J., Holt J., Radzevicius S. and Vendl M.2000. Electromagnetic induction and GPR measurements for creosote contaminant investigation, Journal of environmental and Engineering Geophysics, 5, 11-19.

Kim J.H. 2000. DC2DPro-2D interpretation system of DC resistivity tomography, User's Manual and Theory KIGAM, S. Korea.

Leucci G. 2002. Ground penetrating radar survey to map the location of buried structures under two churches, Archaeological Prospection, 9, 217-228.

Li Y. and Oldenburg D.W. 1992. Inversion of DC resistivity data using an approximate inverse mapping, Geophysical Journal International, 116, 527-537.

Linford N. 2004. From hypocauset to hyperbola: Ground penetrating radar surveys over mainly Roman remains in the U.K., Archaeological Prospection, 11, 237-246.

Ogilvy R.D., Meldrum P.I., Kuras O., Wilkinson P.B., Chambers J.E., Sen M., Pulido-Bosch A., Gisbert J., Jorreto S., Frances I., and Tsourlos P. 2009. Automated monitoring of coastal aquifers with electrical resistivity tomography, Near Surface Geophysics, 7, 367-375.

$\underline{\text { XLVII, No } 3-1364}$ 
Papadopoulos N.G., Tsourlos P.I., Tsokas G.N. and Sarris A. 2006. Two-dimensional and threedimensional resistivity imaging in archaeological site investigation, Archaeological Prospection 13(3), 163-181.

Papadopoulos N.G., Tsourlos P., Tsokas G.N.and Sarris A. 2007. Efficient ERT measuring and inversion strategies for 3D imaging of buried antiquities, Near Surface Geophysics, 5, 349361.

Piro S., Goodman D. and Nishimura Y. 2003. The study and characterization of Emperor Traiano's Villa (Altopiani di Arcinazzo, Roma) using high-resolution integrated geophysical surveys, Archaeological Prospection, 10, 1-25.

Savvaidis A., Tsokas G.N., Liritzis Y. and Apostolou M. 1999. The location and mapping of ancient ruins on the castle of Lefkas (Greece) by resistivity and GPR methods, Archaeological Prospection, 6, 63-73.

Solla M., Lorenzo H., Novo A. and Rial, F.I. 2010. Ground-penetrating radar assessment of the medieval arch bridge of San Antón, Galicia, Spain, Archaeological Prospection, 17, $223-$ 232.

Spikes V.B., Hamilton G.S., Arcone S.A., Kaspari S. and Mayewski, P.A. 2004. Variability in accumulation rates from GPR profiling on the West Antarctic plateau, Annals of Glaciology, 39, 238-244.

Tripp A., Hohmann G. and Swift C. 1984. Two-dimensional resistivity inversion, Geophysics, 49, 1708-1717.

Tsokas G.N., Giannopoulos A., Tsourlos P., Vargemezis G., Tealby J.M., Sarris A., Papazachos C.B. and Savopoulou, T. 1994. A large scale geophysical survey in the archaeological site of Europos (N. Greece), Journal of Applied Geophysics, 32, 85-98.

Tsokas G.N., Stampolidis A., Mertzanidis I., Tsourlos P.I., Hamza R., Chrisafis C., Ambonis D. and Tavlakis I. 2007. Geophysical exploration in the church of Protaton in Karyes of Mount Athos (Holy Mountain) in Northern Greece, Archaeological Prospection, 14, 75-86.

Tsokas G.N., Tsourlos P.I. and Papadopoulos N. 2008a. Electrical resistivity tomography: a flexible technique in solving problems of archaeological research. In Seeing the Unseen, Campana, S. and Piro, S. (eds), Geophysics and Landscape Archaeology, ISBN 978-0041544721-8, 83-104.

Tsokas G.N., Tsourlos P.I., Vargemezis G. and Novack M. 2008b. Non-destructive electrical resistivity tomography for indoor investigation: the case of Kapnikarea Church in Athens, $\mathrm{Ar}$ chaeological Prospection, 15, 47-61.

Tsourlos P.I.1995. Modeling, interpretation and inversion of multielectrode resistivity survey data, Ph.D. Thesis, Department of Electronics, University of York.

Tsourlos P., Ogilvy R., Meldrum P., and Williams G. 2003. Time-lapse monitoring in single boreholes using electrical resistivity tomography, Journal of Environmental and Engineering Geophysics, 8, 1-14.

Tsourlos P. and Tsokas G.N. 2011. Non-destructive electrical resistivity tomography survey at the South walls of the Acropolis of Athens, Archaeological Prospection, 18, 173-186.

Vargemezis G., Tsourlos P. and Stamoulis K. 2007. Application of Geophysical Methods to the study of the Mechanism of Springs, Bull. Geol. Soc. Greece, XXXVII, 605-615.

Vargemezis V., Zouros N., Tsourlos P.I. and Fikos I. 2009. High-resolution magnetic gradient and electrical resistivity tomography survey at the Plaka Petrified Forest Park in Lesvos Island, Greece, Near Surface Geophysics, 7, 207-215.

Yi M.J., Kim J.H., Song Y., Cho S.L., Chung S.H. and Suh J.H. 2001. Three-Dimensional Imaging of Subsurface Structures using Resistivity Data, Geophysical Prospecting, 49, 483-497. 